\title{
NOTAÇÕES PARA UMA HISTÓRIA DA PINTURA NA AMÉRICA LATINA
}

\section{Resumo}

\author{
Rosângela Miranda Cherem \\ Centro de Artes - UDESC
}

Este artigo é constituído de três notações para uma história da arte na América Latina, considerando o arsenal pictórico produzido entre meados de século XIX e primeira metade do século XX. Trata-se de empreendimento inicial que pretende delinear alguns sentidos para a imagem, especialmente considerando aquelas obras em que o corpo feminino apresenta de modo mais explícito certas sensibilidades e percepções inerentes ao pensamento plástico, bem como esboçar uma problemática sobre o arsenal imagético e suas possibilidades de abordagem, particularmente no que se refere a questões relacionadas à cronologia e anacronismo, texto e contexto, cópia e original, proximidade e distância, superfície e profundidade.

Palavras-chave: História da arte; sensibilidades e percepções; imagem pictórica.

Notations for a history of the painting in Latin America

\begin{abstract}
This article is constituted by three notations to an Art History in Latin America, considering the pictorial arsenal produced in the XIX century and in the first half of the XX century. This is the first enterprise that intends to sketch some senses to the image, specially considering those works in which the feminine body presents in a more explicit way some sensibilities and perceptions inherent to the plastic thought, as well as to outline a problematic about the imagistic arsenal and its approach possibilities, specially in what refers to questions related to chronology and anachronism, text and context, copy and original, proximity and distance, superficies and depth.
\end{abstract}

Keywords: Art History, sensibilities and perceptions, pictorial images. 
I - Primeira notação. Muito já se falou sobre o fato de que os países latinoamericanos possuem elementos históricos comuns associados ao passado colonial e escravista, aos vínculos com as metrópoles ibéricas e à definição de desejos de ruptura em relação às mesmas. Tais países também partilham as injunções do neo-colonialismo e a emergência imperialista, além de certas expectativas e articulações com as experiências vanguardistas. Porém, considerando tais especificidades, observa-se uma escassez de estudos e pesquisas no campo da História da Arte, impossibilitando tanto um entendimento mais rico da produção artística, como impedindo avanços para além dos catálogos e estudos sobre acervos privados e/ou monotemáticos. Neste sentido, trata-se tanto de gerar novos estudos e potencializar reflexões sobre as artes plásticas no âmbito da modernidade, reconhecendo nuances nascidas na relação de semelhança-diferença neste meio, como de abordar o modernismo para além de leituras auto-centradas, excessivamente engessadas em termos cronológicos ou que registram apenas os vínculos europeus ou norte-americanos. Assim, para encontrar a chave é preciso primeiro revirar os bolsos, reconhecendo seu conteúdo e enfrentando perguntas como: em que medida pode a obra de artistas pouco conhecidos e de reduzida fortuna crítica tornar-se objeto de reflexão e leitura? Como reincidir o periférico e o pouco qualificado sem cair na visada monótona e exaustiva das abordagens já feitas? Como construir um campo de análise onde o que prevalece e pode ser pensado incide sobre o estranho que escapa e surpreende bem ali onde uma luz já posta parece apenas indicar o já conhecido?

Um primeiro aspecto para abordar as pinturas latino-americanas pode ser deslindado a partir dos escritos do Conde de Buffon (1707-1788) em Histoire Naturelle de l'homme, onde foram apresentadas as distinções filosóficas entre a Europa e o Novo Mundo. Interessado em apreender a verdadeira natureza humana à luz da biologia, este iluminista contemporâneo das ambições enciclopedistas dividiu a espécie humana em quatro raças distintas: europeus, chineses, negros e americanos. Comparando as demais com a primeira, formulou os fundamentos da superioridade do colonizador, justificando a superioridade do civilizado e de seu empreendimento. Em conformidade com as molduras classificatórias confirmava a episteme moderna e suas bases heteróclitas quando, por exemplo, observou que na América o clima é mais úmido e por isso seus habitantes não possuem cabelo crespo e nem barba e por esta razão são também mais indolentes e fazem armas inferiores as da Europa. A atmosfera imperfeita e mais imatura igualmente seria responsável por fazer os europeus degenerarem mais rapidamente neste continente.

Por sua vez, uma consideração de dupla face parece se destacar neste texto de Buffon, assinalando os riscos que corre o estudioso dos fenômenos de 
um continente. De um lado espreita a homogeneização das diferenças, perigo oposto ao da singularização extremada, eixo que ignora a articulação entre as diferenças e as repetições mantendo o investigador refém do paradoxo universal-particular. Do outro lado aguarda uma operação de catalogação que apenas busca familiarizar o diverso e tudo observa em relação ao mundo já conhecido. Aspecto que tanto assume a constatação da inferioridade de um ponto em relação a outro, como pode se configurar apenas enquanto esforço para reparar nomes injustiçados ou feitos ignorados, encontrando-lhes um lugar no pódio do ressarcimento da verdade histórica. Todavia à luz da problemática ensejada por Buffon e dos riscos que para ela confluem, parece interessante considerar a produção artística na América Latina através de um procedimento de báscula, onde as imagens se articulam para além das leituras formalistas e também das contextuais ou da relação simplificadora entre vida e obra, mapeando questões contidas nas obras e engendrando problemas reconhecidos nas séries imagéticas.

Operando e ao mesmo tempo interrogando os procedimentos da história da arte, considere-se uma primeira combinação pelo angulo da teoria e crítica das imagens. São retratos de duas mulheres* com o mesmo nome, pertencentes a um mesmo país mas separadas por um século, portanto, iguais mas diferentes não só pelos destinos e contextos que ultrapassam cada tela, mas também pelo fato de que os artistas que as criaram são dois nomes de reconhecida importância histórica que atravessam horizontes sociais e políticos bastante distintos. A este respeito, ao reivindicar uma apreciação da obra de arte em sua própria materialidade e em seus próprios termos, Derrida considera a pintura como algo que surge desde uma debaixo, espécie de trapaça ou jogo de cores e planos sobre superfície, resto cifrado, mas também cifra inútil que opera um segredo no legível, cujo movimento remete a um isso acaba de partir, isso volta a partir, isso acaba de voltar e partirl.

Antes de lançar a fácil comparação dos quadros com as estéticas europeizantes, convém atentar para noção de uma modernidade expandida e ampliada, cujas imagens compõem um repertório visual constituído por e constitutivo de certos jogos de reverberação e rebatimento na qual a diversidade se apresenta,

"Nota das editoras: remetemos os leitores aos sites fornecidos pela autora nos quais pode-se acessar as obras analisadas.

MÉXICO, Juan Cordero. Dona Dolores Tosta de Santa Anna. 1855

Óleo sobre tela, 86 × $59 \mathrm{~cm}$. Museo Nacional de Arte, Cidade do México. http://www.humanitiesinteractive.org/splendors/ex048_ I7c.html

MÉXICO, José Diego Rivera. $1 \overline{9} 55$.

Óleo sobre tela. http://www.myhero.com/myhero/hero.asp?hero=Dolores_Olmedo_Patino 
ao mesmo tempo combinada e difusa, articulada e proliferante, espécie de original sem origem. Tal condição torna possível reconhecer certos esforços de ruptura estética no seio das obras acadêmicas antes mesmo das explicitações vanguardistas, além de situar certas investigações plásticas mais pela concomitância de certas contingências do que como simples ecos europeus. Do mesmo modo, os recortes modernistas situados depois da primeira grande guerra em vários países latinos americanos podem ser lidos como uma construção discursiva em grande parte associada à memória de seus protagonistas, interessados em se contrapor às academias de belas artes como meio para se afirmar numa situação de ruptura com a tradição. Ademais, tudo indica que se as chamadas vanguardas latinoamericanas adotaram freqüentemente bandeiras anti-acadêmicas como parte de seu desejo de aggiornamento é porque ignoravam ou esqueciam os choques produzidos intencionalmente por participantes de salões oficiais europeus, tal como no caso de Manet. Em outras palavras, mesmo dentro de certos circuitos oficiais as posturas inquietas e chocantes, disfarçadas ou não, já se deixavam ver bem antes daquilo que se delimitou como próprio aos tempos pós-primeira guerra.

Se a imagem da Vênus anadiômena pode voltar num corpo mestiço, guardando em seu rosto inocente certa familiaridade com a Vênus de Botticelli, a pose dos braços sinaliza um simulacro do pudor, sendo que o antigo movimento revolto da paisagem e dos cabelos pode agora se deslocar para as pregas de um cortinado que oblitera tanto uma paisagem lançada para uma exterioridade como a própria parede do ambiente. Do mesmo modo, de costas para a árvore do pecado uma Eva tornada fetiche explicita a sexualidade feminina, enquanto o animal que se distancia da cena guarda algo de irreverência e humor que menos remete à ordem edênica e mais à imagética pornográfica, produzindo plasticamente reverberações irônicas que interrogam verdades passadas*

Se no fim do oitocentos Nietzsche iria vaticinar a morte de Deus para falar do fim das certezas e dos grandes sistemas explicativos, desde algumas décadas antes Courbet e Baudelaire tentavam encarar os problemas da carne e do corpo feminino em relação direta com a anti-beleza. Desse modo, o corpo coagulado como matéria artística, literária ou pictórica, emblematiza a carne do mundo e a superfície das coisas, sendo que tanto na Europa como na América Latina tais injunções comparecem, quer no chamado ambiente acadêmico como naquilo que o interrogou e buscou suceder. Porém, para alcançar as pulsações contidas em algumas obras, talvez seja preciso ultrapassar as questões de território e nação, para reconhecer que, por vezes cumprindo certas expectativas e atendendo às

"ARGENTINA. Emílio Centurion. A vênus crioula. 1934

Óleo s/ tela, 183 × $130 \mathrm{~cm}$. Coleção Museo Nacional de Bellas Artes, Buenos Aires.

http://www.mnba.org.ar/obras_autor.php?autor=60\&opcion $=1$. 
encomendas, os artistas conseguiram ultrapassar o caráter ilustrativo e/ou narrativo, guardando naquelas formas todo um universo de inquietações e investigações plásticas que vinham sendo delineados desde o alvorecer moderno.

II - Segunda notação. Como adentrar num arsenal imagético, cujas fontes documentais e registros complementares são demasiado escassos, inacessíveis ou inexistentes? Quais os caminhos possíveis para dar conta deste desafio sem cair nas leituras simplificadoras e banalizantes que confundem imagem com ilustração ou apressam o alcance de suas particularidades diluindo-as logo num conjunto? Para responder a estas inquietações parece importante encarar a difícil tarefa de pensar ao mesmo tempo as imagens e seus arquivos, não só para evitar os meros relatos e classificações, como também para pensar as novas combinações e destinos possíveis para as obras de arte. Considerando-as tanto através de uma espécie de constelação, a qual só existe pelos efeitos de condensação e desvio, como por uma espécie de acoplamento de diferentes temporalidades podese reconhecer nelas a sobrevivência das formas, menos como o que foi herdado e mais como os desdobramentos e as possibilidades resultantes, posto que os acontecimentos como as imagens só podem ser pensados pelos procedimentos de recombinação e montagem. Por sua vez, para evitar os perigos da redundância, talvez seja conveniente neste ponto contornar as considerações benjaminianas relativas ao inconsciente ótico e aos procedimentos de montagem, bem como a concepção foucaultiana de arquivo relacionado às exceções e desvios, descontinuidades e faltas, cujas sombras e silêncios nada têm de neutro ou ingênuo. Tal contorno permite problematizar os arquivos e os possíveis procedimentos de leitura construindo um campo situado entre a série abordada como repetição com diferença e o museu imaginário considerado como arsenal infinito e único de afecções.

Refletindo sobre o fato de que a falência de representação no pensamento moderno faz com que todas as identidades sejam simuladas e produzidas como efeito ótico sob o jogo da diferença e repetição ${ }^{2}$, Deleuze destaca que a diferença se constitui como aquilo que nem está subordinado ao idêntico, nem é sua negação, nem se refere à oposição nem se constitui como contradição. Em seguida relaciona a repetição ao pensamento nietzscheano no qual Zaratrusta se distingue da simples generalidade uma vez que enquanto esta obedece a leis com permanências e variáveis constantes possibilitando que um termo possa ser traduzido por outro e o particular possa ser reposto e substituído, posto que seja indeterminado e indiferenciado, a repetição se coloca como vibração secreta, desvio ou transgressão de uma potência singular que ocorre como desvio entre generalidades. Assim a repetição e o retorno tornam-se uma espécie de potência que contém tanto a perdição como a salvação, não sendo nem uma generalidade 
produzida pelo hábito, nem uma particularidade de memória, permitindo inventar gravitações e saltos para agir em função daquilo que não se é e nem se tem. Eis porque as obras, como os artistas, devem ser consideradas na relação com as séries que procuram menos a generalidade e mais os vestígios da diferença e da repetição. Sendo a arte o lugar onde as diferentes repetições coexistem, a repetição é diferença sem conceito, não porque se constitui como reprodução do mesmo e sim porque é arremesso em direção ao outro.

Por sua vez, André Malraux ${ }^{3}$ lembra que o museu imaginário é um fenômeno do mundo moderno, particularmente ampliado com a reprodutibilidade técnica, a qual possibilita não só acessar diferentes acervos como também estabelecer novas comparações e agrupamentos, ordenações e classificações. Acrescentando novas iluminações às imagens, reativando sua potência e colocando-as em constante movimento, trata-se de refletir menos sobre aquilo que um dia disseram e mais sobre o que ainda podem nos dizer. Face à ordem catalográfica já dada, o que conta são menos os significados fechados e mais os lapsos, dilemas e irresoluções de seus portadores, avistados em certos rasgos produzidos pelo manuseio documental, cujas fontes se des-hierarquizam e embaralham incessantemente. Profanando verdades legitimadas ou avançando sobre indefinições, operase por uma indébita appropriatio, combinando e sobrepondo, rearticulando códigos e evitando simplesmente repetí-los.

Considere-se uma pequena coleção de nus deitados como uma meta-linguagem pictórica."

Dispostos em série tornam-se corpus e para além de ratificar a relação de beleza com a arte através das figuras femininas erotizadas desde as Vênus re-

\footnotetext{
* PERU. Luis Montero. Venus adormecida. I851.

Óleo s/ tela, $82 \times 123 \mathrm{~cm}$, Museu Nacional de Arqueologia, Antropologia e História http://www.limaeasy.com/museums/museodearte.html

MEXICO. Felipe Gutiérrez. A caçadora dos Andes. 1891. Óleo s/tela, 100 × $162 \mathrm{~cm}$. Museu Nacional de Arte, Cidade do México

http://redescolar.ilce.edu.mx/redescolar/proyectos/acercarte/arte_mexicano/artemex5/ mexexp05a3.htm

BRASIL. Rodolfo Amoedo. Estudo de mulher. 1884. óleo sobre tela, I 50 × 200 cm. Museu Nacional de Belas Artes do Rio de Janeiro.

http://www.dezenovevinte.net/bios/bio_ra_arquivos/ra_I884_estudo.jpg

COLÔMBIA. Eugenio Zerda. Nu. $194 \overline{5}$

Óleo s/ tela, 70x107cm. Museu Nacional da Colômbia.

http://www.indetectable.org/pages/noticias/in24.pdf

URUGUAI. Juan Manuel Blanes. Demônio, mundo e carne. 1885 - Óleo s/ tela. I,06 x

I,56 cm. Coleção Museu Municipal Juan Manuel Blanes.

http://www.montevideo.gub.uy/museoblanes/blanes.htm

PERU. Daniel Hernandez. Nu Reclinado. 1899. Óleo s/ tela, 93,3 × 151, I cm.

http://www.artnet.com/artist/8I 59/daniel-hernandez.html
} 
nascentistas, remetem aos procedimentos pictóricos que se pensam a si próprios, auto-referenciando-se enquanto jogos de linha e textura, volume e forma, luz e cor, portanto opus. Por sua vez, se como ensina Deleuze cada artista compõe e recompõe a sua maneira uma história da pintura ${ }^{4}$, em certas pinturas, ressurge a imagem escultórica feminina remota deitada sobre o túmulo ou recostada nos divãs dos afrescos pompeianos. Assim, situadas desde a segunda metade do século XIX, as pinturas que aqui comparecem tanto remetem a um ponto pretérito, cujas remotas vibrações ainda lhes afetam como indicam certas prefigurações advogadas pelos modernistas do século XX. Neste caso, trata-se de considerar uma história das sensibilidades e percepções sobre as imagens que se reconhece em 'des-tempos' e para onde incidem tanto questões bastante antigas, tal como as registradas por Plínio, o velho acerca das dispustas entre Zeuxis e Parrásios ao definir a superfície pictórica como cortina, véu e ilusão ${ }^{5}$; como para onde incidem questões mais recentes, considerando-se as propostas vanguardistas de uma arte auto-referente e que recusa a mera reprodução do mundo visual ${ }^{6}$.

Embora a titulação da obra só possa ser problematizada como correspondência e não como equivalência, posto que dizer não seja ver e entre ambas as instâncias o que se coloque é um abismo ${ }^{7}$, convém prestar atenção ao gesto através do qual, por vezes o artista considera a legenda como uma espécie de seta, sinalizando para uma narrativa precedente e exterior à pintura, enquanto noutras ocasiões prefira deter-se mais sobre o conteúdo pictórico. Eis a consistência que desfaz o mundo ótico e propõe um jogo de tensões dinâmicas, variações lógicas e modulações coloridas que se recusa a ser ilustração de um corpo reapresentado ao mesmo tempo em que se produz o colorido da carne pictórica. É assim que, vulneráveis em seu estado absorto, frágeis em seu sossego instável, entregues à languidão, incônscios ou perturbados pelo olhar alheio, os corpos nascem ora como pretexto para as fantasias dos espectadores ${ }^{8}$, ora como objeto das mais diversas experimentações plásticas ${ }^{9}$, tornando-se ora corpo que tenta escapar através de um ponto de fuga, insinuando um tempo-espaço que se abre e se fecha sobre aquilo que ali se apresenta, ora jogo de fragmento e forma, mancha e cor viva, que nada pretende aludir para além ou atrás de $\mathrm{si}^{10}$. Estendidos na

\footnotetext{
ARGENTINA. Antonio Berni. Susana e o velho. 1931

http://www.oni.escuelas.edu.ar/olimpi98/juanitoyramona/laetapa.htm

COLÔMBIA. Ignacio Gómez Jaramillo. A dama Vestida de Blanco. 1937

Óleo sobre tela, $64.5 \times 80 \mathrm{~cm}$

http://www.villegaseditores.com/loslibros/9588 160472/

PARAGUAI. José Parodi. A televisão me aborrece. 2003.

Técnica mista, $100 \times 70 \mathrm{~cm}$.

http://www.rosariarte.com.ar/p/parodi/00 I 058.htm
} 
paisagem natural ou espalhados nos labirintos do leito, onde a maciez de sua pele tanto acolhe o olhar que a atravessa como contrasta com sua intimidade avassalada, aqueles corpos não apenas se colocam na relação proximidade-distância com o mundo alhures à tela, como também interrogam aquele mundo, retornando para a propriedade da pintura de fazer ser aquilo que ela não é, permitindo que aquele que se situa diante dela possa percorrê-la através de uma espécie de percurso tátil do olhar.

III - Terceira notação. Uma vez acessado o arsenal e constituída a série de imagens, com quais fios pode o historiador tecer sua trama? Como evitar a armadilha da diluição das singularidades em contextos homogeinizadores e extrínsecos e/ou das particularidades isoladoras e desconectadas que ignoram a formulação-armação de problemas? Como produzir um campo fértil de reflexões, contornando tanto uma história da arte cronológico-evolutiva como presa à sentidos já dados, mas considerando ainda assim as questões que reverberam no tempo e no espaço, as quais de um modo renitente nos afetam? Tal possibilidade parece tornar-se particularmente interessante se as obras enfocadas não pertencerem ao repertório legitimado, mas puderem ser reconhecidas pelo seu caráter de recorrência e sobrevivência. É então que comparece a noção de sintoma como aquilo que interroga a imagem em sua relação com o tempo, interrompendo o fluxo regular das coisas e tornando-se uma espécie de lei avariada e subterrânea que persiste como retorno de uma enfermidade. Nem conceito semiológico, nem conceito clínico, trata-se de uma noção operatória que recusa submissão ao tempo eucrônico, destacando-se como aparição de uma latência que conjuga diferença e repetição, proximidade e distância, interior e exterior, imobilidade e aceleração ${ }^{11}$.

Exercício de sofisticação dos efeitos de realismo considere-se os retratos* que demandam outra instância para pensar o visível, ultrapassando as evidências do visual. Neste empreendimento visível e invísível se imbricam e articulam mais

\footnotetext{
* MÉXICO. Saturnino Herrán. Mulher com abóbora. 1917.

Mista s/ papel, $57 \times 39 \mathrm{~cm}$.

http://www.museoblaisten.com/Znglish.asp?myURL=\%2F02asp\%2FEnglish\%2FartistDetailEnglish\%2 Easp\&myVars = artistld\%3D47

EQUADOR. Juan manosalvas. Senhora

Óleo sobre tela

http://www.edufuturo.com/educacion.php?c $=1789$

URUGUAI. Frederico Renon. Estudo. 1890

Óleo s/ tela - 43 × 36,5 cm. Coleção Museu de ArtesVisuais.

http://www.mnav.gub.uy/academ.htm

EQUADOR. Camilo Egas. Cabeça de Índia. 1926

Óleo sobre madeira, $38 \times 45 \mathrm{~cm}$

http://www.dlh.lahora.com.ec/paginas/mejores/contenido.htm
} 
do que se contrapõem, enquanto recusam sua redução à mera atividade da visão, fazendo com que as linhas e pigmentos sobre a superfície da tela produzam efeitos de cintilação através de um jogo de texturas e dobras, volumes e estampas, remetendo aos recursos do intersticial.

Conforme Didi-Huberman a pintura pensa e talvez essa seja uma questão infernal para o pensamento ${ }^{12}$, afirmação que tanto permite pensar a imagem pelo recurso do anacronismo, em conformidade com as reflexões de Warburg e Benjamin acerca das impurezas temporais, como também se aproxima da temática das ruínas circulares e dos labirintos borgeanos. Situando as experiências humanas para além dos meros enquadramentos e continuidades cronológicos, as imagens como os acontecimentos passam a ser concebidos como sonhos renitentes ou questões irresolutas que retornam sob certas injunções e contingências, persistindo e insistindo como ondas mnemônicas. Fluxo e refluxo, beleza e caos, criação e destruição, pintura do mundo e assassinato da coisa, mundo da pintura e simbolização da ausência, eis o movimento pendular que percorre das convenções mais realistas às experimentações mais ousadas*. Constituído num entre, o espaço onde estes corpos adquirem vida através da materialização de certas inquietações plásticas acaba por produzir um esquecimento do fato de que toda pintura é mancha e que cada curva ou ângulo corporal, cada cor ou fragmento não passa de um delírio pelo qual a superfície da tela encena uma interrogação sobre a conversibilidade do mundo e a impenetrabilidade das coisas.

Assim, trata-se de pensar a pintura como operação que desde o seu mais remoto nascimento demanda um jogo entre superfície-profundidade e proximida-

\footnotetext{
* CHILE. Marco Aurélio Bontá Costa. Infancia De Júpiter. Museo de Arte Contemporáneo, Universidad de Chile, Santiago http://www.mac.uchile.cl/virtual/galerias/desnudo2.html BRASIL. Eliseu Visconti. Mãe e filho. 1940

Óleo sobre tela - $46 \times 65 \mathrm{~cm}$

http://www.arteeeventos.com.br/paginas_leilao/categoria.asp?iCat $=353 \&$ offset $=102$ ARGENTINA. Eduardo Sívori . El despertar de la criada. 1867

Óleo s/ tela, I,92 × 1.31 m, Museu Nacional de Belas Artes http://biografias0.iespana.es/biografias0/generacion_del_80.htm COLÔMBIA, Miguel Díaz Vargas. Estudo em Cinzas. $19 \overline{9} 4$.

Óleo s/ tela, I1 0x90 cm.

Museu Nacional da Colômbia

http://www.indetectable.org/pages/noticias/calidadarv.htm

ARGENTINA, Ernesto de la Cárcoba. Sorpresa. 1896

http://static.pagina I 2.com.ar/fotos/espectaculos/200707/7/notas_e/na29fo02.jpg

ARGENTINA. Héctor Baldasua. Figura (Elianne de Courcelles). 1928

Óleo s/ tela 79,5 × 60 cm. Coleção Museu Nacional de Bellas Artes, Buenos Aires.

http://www.fundacionkonex.com.ar/bienales_del_arte/basaldua_hector.asp
} 
de-distância, invocando a pele e a carne através de um encobrimento situado entre a aparição e a ocultação, a cobertura e a revelação. Eis aquilo a que se poderia chamar de mirabilia ou magia de figurabilidade como gesto produtor de um corpo dotado de intensidade, capaz de proporcionar um delírio de penetração visual e aderência do olhar através de um trânsito entre fulguração e vestígio, sublimidade e burla, guardando uma relação fantasmática com aquele que a executa e o mundo ao qual pertence. Eis também como academicismo e modernismo se desfazem como rótulos, enquanto preservam elos com uma distante história da experiência visual e alimentam o entendimento de que toda a criação possui seu duplo não na originalidade nascida de um ponto zero ou a partir de uma ultrapassagem, mas sim na repetição e retorno de remotos problemas que se refazem incessantemente para voltar como desvio e diferença, lapso e esquecimento.

Recebido em 07 de abril de 2008

\section{NOTAS}

' DERRIDA, Jacques. La vérité en peinture. Paris: Flammarion, 1978, p. 463.

${ }^{2}$ DELEUZE, Gilles. Diferença e repetição. R.J.: Graal, 1988, cap. I e II.

3 MALRAUX, André. O museu imaginário. Lisboa: Ed. 70, 2000, cap. III e IV.

${ }^{4}$ DELEUZE, Gilles. A lógica da sensação. R.J.: Zahar, 2007, p. 123 e seg.

${ }^{5}$ SALCEDO, M. E. ( org. ). Plínio. Textos de historia de la arte. Madri: Ed. A. Machado Libros, 2001.

${ }^{6}$ KRAUSS. Rosalind. La originalidad de la vanguardia Y otros mitos modernos. Madrid: Alianza, 1996.

${ }^{7}$ BLANCHOT, Maurice. A conversa infinita. S.P.: Ed. Escuta, vl. I , 2001.

${ }^{8}$ MEICHES, M. Catálogo da exposição. O desejo na Academia, 1847 - 1916. PINACOTECA DE S.P., PW, 1991.

9 GRUPO VELOX ( Org.). Pintura latinoamericana. Buenos Aires, Ed. El Ateneo, 1999.

10 DIDI-HUBERMAN, Georges. La Venus rajada. Madri: Ed. Losada, 2005.

" DIDI-HUBERMAN, Georges. Ante el tiempo. Buenos Aires: Adriana Hidalgo, 2006.

12 DIDI-HUBERMAN, Georges. La peinture incarnee. Paris: Les Éditions de Minuit, 1995. 